\title{
THE PROBLEM OF THE YEARLY INFLATION RATE AND ITS IMPLICATIONS FOR THE MONETARY POLICY OF THE CZECH NATIONAL BANK
}

\author{
Josef Arlt, Milan Bašta
}

\begin{abstract}
:
The yearly inflation rate might not always be an appropriate measure of inflation, mainly due to the fact that it does not provide up-to-date information on the level of inflation. The harmonic analysis shows that the yearly inflation rate deforms and delays the information with respect to the monthly inflation rate and is thus delayed behind the true inflation at yearly levels. This conclusion can be extremely important in the forecasting of the inflation rate at yearly levels and in the process of economic decision making. The problem of the yearly inflation rate is illustrated on the example of the monetary policy of the Czech National Bank. The cointegration analysis revealed the presence of the long-run relationship of the repo rate, the yearly adjusted inflation rate and the euro area repo rate in the analyzed period.
\end{abstract}

Keywords: inflation rate, harmonic analysis, linear filtration, forecasting, monetary policy.

JEL Classification: C22, E31, E43, C52

\section{Introduction}

Inflation is a very important macroeconomic indicator measuring the change in the general level of prices of goods and services consumed by households. It plays a crucial role in the monetary policy, specifically in the inflation targeting through interest rates setting. It is used for the calculation of real interest rates, the increase of the real value of assets, the valorization of wages, pensions and social benefits.

* University of Economics Prague, Department of Statistics and Probability, Czech Republic (arlt@vse.cz, milan.basta@vse.cz). This paper was written with the support of the Grant Agency of the Czech Republic No. P402/10/0289. 
Due to the widespread use of inflation and its significant role in economy, it is of utmost importance to find a good measure of inflation. In this paper we argue that the widely used measure of inflation, specifically the yearly inflation rate (introduced below) might not always be an appropriate measure, mainly due to the fact that it does not provide up-to-date information on the level of inflation.

The measure of inflation is based on the consumer price index (CPI) which is the indicator of the general level of prices of goods and services consumed by households. The Czech Statistical Office uses the Laspeyres index to calculate the consumer price index, i.e.

$$
C P I_{t} \equiv \frac{\sum p_{t} q_{B}}{\sum p_{B} q_{B}} .
$$

Variables " $p$ " and " $q$ " stand for the prices and quantities of goods and services. The subscript " $B$ " denotes the base period and the subscript " $t$ " denotes the current period. Calculating $\mathrm{CPI}_{t}$ month by month, we get a monthly time series of the consumer price index.

Inflation is informally defined as the change in the consumer price index during the period of either one month or one year - this definition leads to either the monthly or the yearly inflation rate. To be more rigorous, the monthly time series of the monthly inflation rate is defined as

$$
I R_{m, t} \equiv \frac{C P I_{t}}{C P I_{t-1}}
$$

This definition implies that the time series of the monthly inflation rate is the growth rate (of the monthly time series of the consumer price index) with respect to the previous month. Similarly, the monthly time series of the yearly inflation rate is defined as

$$
I R_{y, t} \equiv \frac{C P I_{t}}{C P I_{t-12}} .
$$

This definition means that the time series of the yearly inflation rate is the growth rate (of the monthly time series of the consumer price index) with respect to the corresponding month of the previous year. ${ }^{1}$

All the time series in this paper (e.g. the time series of the consumer price index, the time series of the monthly inflation rate and the time series of the yearly inflation rate) are measured month by month and are thus monthly time series. Therefore, we will often omit the adjective 'monthly' and also the phrase 'time series'. Instead of writing e.g. 'the monthly time series of the yearly inflation rate', we might briefly write 'the yearly inflation rate'. Only for purpose of emphasis and/or understandability the full phrase might be left untouched in some sentences.

In Figure 1 we present the consumer price index $C P I_{t}$, the monthly inflation rate $I R_{m, t}$ and the yearly inflation rate $I R_{y, t}$ of the Czech Republic from January 1997 till September 2009 and the natural logarithms of these time series, i.e. $\log C P I_{t}$, $\log I R_{m, t}$ and $\log I R_{y, t}$. The reason for the use of the logarithms will be described in a more detail in the text below.

1 In the economic literature the yearly inflation rate is defined as $\left(C P I_{t}-C P I_{t-12}\right) / C P I_{t-12}=I R_{y, t}-1 \approx \log I R_{y, t}$ and the monthly inflation rate as $\left(C P I_{t}-C P I_{t-1}\right) / C P I_{t-1}=I R_{m, t}-1 \approx \log I R_{y, t}$. 
Figure 1

The Consumer Price Index (CPI), the Monthly $\left(\mathrm{IR}_{\mathrm{m}}\right)$ and the Yearly $\left(I \mathrm{R}_{\mathrm{y}}\right)$ Inflation Rates and the Logarithms of these Time Series from January 1997 to September 2009
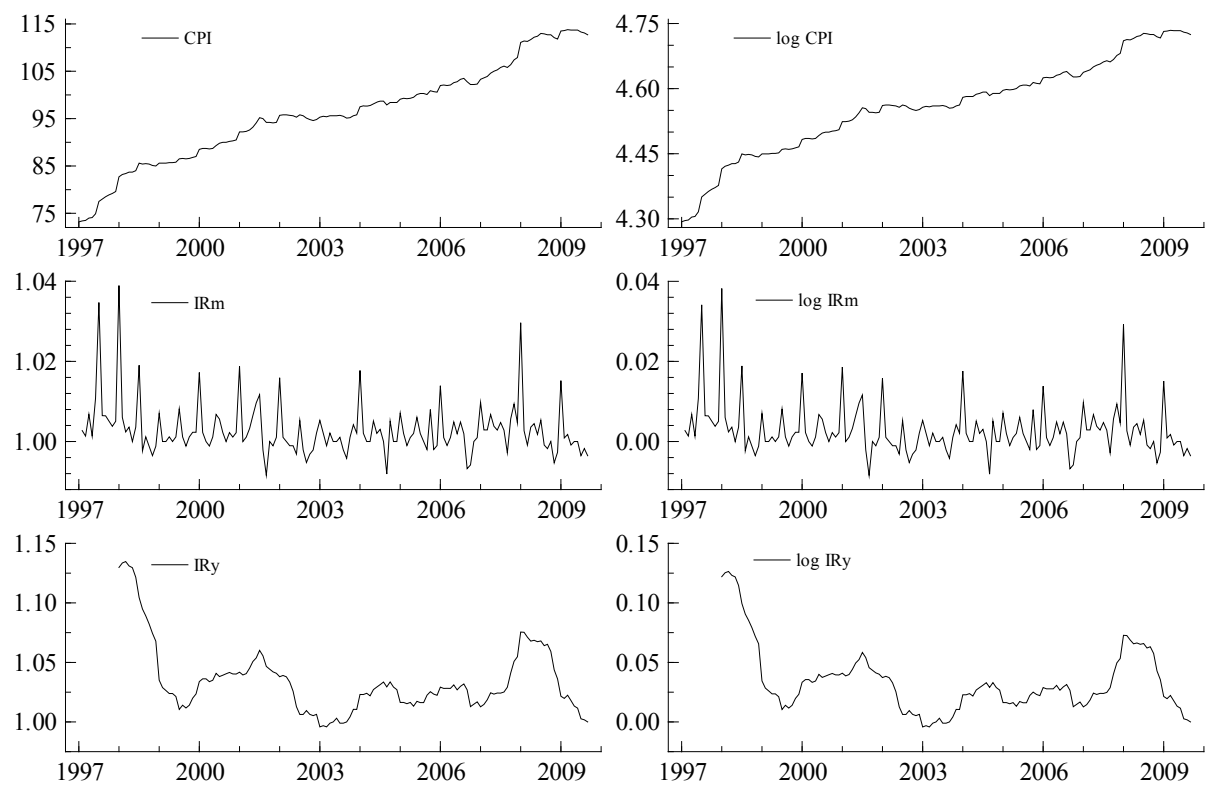

Source: own calculations, Čsú (2009)

\section{The Seasonality of the Monthly and Yearly Inflation Rates}

First, let us note the seasonal pattern in the time series of the monthly inflation rate $\left(I R_{m, t}\right)$. This pattern can be seen with some effort with a naked eye exploration of Figure 1 and becomes prominent if a specific model is fit to the time series of the monthly inflation rate.

For ease of exposition let us assume the following model of multiplicative seasonality of the monthly inflation rate

$$
I R_{m, t}=T_{t} \times S_{t} \times \varepsilon_{t} .
$$

$T_{t}$ stands for the trend and cycle at time $t, S_{t}$ is the seasonal effect at time $t$ and $\varepsilon_{t}$ is the random error at time $t$. The existence of seasonality in the time series of the monthly inflation rate might be undesirable under some circumstances where the knowledge of the trend and cycle is required to know. One (but not the best) way to get rid of the seasonality and random fluctuations is to use the time series of the yearly inflation rate. To see the point, note the connection between the yearly and the monthly inflation rates

$$
I R_{y, t}=I R_{m, t} \times I R_{m, t-1} \times \ldots \times I R_{m, t-10} \times I R_{m, t-11} .
$$


This means that

$$
I R_{y, t}=\prod_{i=0}^{11} I R_{m, t-i}
$$

where the capital Greek letter $\prod$ stands for the product, i.e. the result of multiplying of several factors. Based on equation (6) we can observe that the time series of the yearly inflation rate is the moving product (of the time series of the monthly inflation rate). The seasonal effects will be removed in the time series of the yearly inflation rate if it holds that

$$
\prod_{i=0}^{11} S_{t-i}=1
$$

i.e. if the seasonal effects $S_{t}$ cancel out in a multiplicative manner (i.e. their product is 1). The fulfillment of the condition (7) indeed implies that

$$
I R_{y, t}=\prod_{i=0}^{11} I R_{m, t-i}=\prod_{i=0}^{11}\left[T_{t-i} \times S_{t-i} \times \varepsilon_{t-i}\right]=\prod_{i=0}^{11}\left[T_{t-i} \times \varepsilon_{t-i}\right] \approx \prod_{i=0}^{11} T_{t-i}
$$

which means that $I R_{y, t}$ is free of seasonal effects. The approximate equality $(\approx)$ in the last equation holds if the product of random errors is approximately one.

\section{Logarithmic Scale}

An alternative way to see the above point is to work with logarithms of the time series (which are depicted in the right-hand column of Figure 1). Taking the logarithm of the equation (6) results in

i.e.

$$
\log I R_{y, t}=\log I R_{m, t}+\log I R_{m, t-1}+\ldots+\log I R_{m, t-10}+\log I R_{m, t-11}
$$

$$
\log I R_{y, t}=\sum_{i=0}^{11} \log I R_{m, t-i} .
$$

The log yearly inflation rate is therefore the moving sum (of the log monthly inflation rate). Again the same line of thought as above applies. Working in the logarithmic scale the model with multiplicative seasonality of the equation (4) converts into the model with the additive seasonality

$$
\log I R_{m, t}=\log T_{t}+\log S_{t}+\log \varepsilon_{t} .
$$

This additive seasonality will be removed in the time series of the log yearly inflation rate if

$$
\sum_{i=0}^{11} \log S_{t-i}=0
$$

i.e. if the log seasonal effects cancel out in an additive manner (i.e. add up to 0), which always occurs if the condition of the equation (7) is fulfilled. If this is the case then 


$$
\begin{aligned}
& \log I R_{y, t}=\sum_{i=0}^{11} \log I R_{m, t-i}=\sum_{i=0}^{11}\left[\log T_{t-i}+\log S_{t-i}+\log \varepsilon_{t-i}\right]=\sum_{i=0}^{11}\left[\log T_{t-i}+\log \varepsilon_{t-i}\right] \\
& \approx 12 \log T_{t},
\end{aligned}
$$

i.e. $\log I R_{y, t}$ is free of seasonal effects. Again, the approximate equality $(\approx)$ in the last equation holds if $T_{t} \approx T_{t-1} \approx \ldots \approx T_{t-11}$ and if the sum of $\log$ random errors is approximately 0 .

For further discussion we will prefer to use the logarithms of the time series. The reason for this choice is the fact that the connection between the log yearly inflation rate and $\log$ monthly inflation rate in the summation form of the equation (8) is much more appealing and practical for our purpose (as will also be shown below) than the connection between the yearly inflation rate and the monthly inflation rate in the product form of the equation (5). Moreover, the following flow diagram holds which interconnects the operations in the original and logarithmic scale

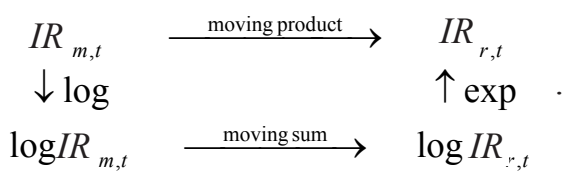

We see that applying the moving product of the equation (5) onto the monthly inflation rate and obtaining the yearly inflation rate as a result, is the same as applying the following flow of three operations onto the monthly inflation rate: 'logarithm -> moving sum -> exponential'. Logarithm and exponential are 'trivial' operations, and the most interesting and crucial operation in this chain of three operations is the moving sum. Therefore, the analysis of the relation of the log monthly and log yearly inflation rate (which are related by this moving sum) is sufficient to study. Moreover, the time series of the log monthly and the log yearly inflation rates can be easily converted to the original scale by taking the exponential of these time series.

\section{The Harmonic Analysis and Linear Filtration}

An elegant way to see that seasonality is removed in the log yearly inflation rate is the use of the apparatus of Fourier transform, harmonic analysis and linear filtration (details on these tools can be found e.g. in Percival, 1993). We will describe this concept in an informal way. It tells us that time series $x_{t}, t=0, \ldots, N-1$, of length $N$ can be represented as a sum of sines of different frequencies $f_{k}$, different amplitudes $A_{k} \geq 0$ and different phases $\varphi_{k}$

$$
x_{t}=\sum_{k=0}^{\lfloor N / 2\rfloor} A_{k} \sin \left(2 \pi f_{k} t+\varphi_{k}\right), \quad t=0, \ldots, N-1,
$$

where $f_{k}=k / N, k=0, \ldots,\lfloor N / 2\rfloor$, where $\lfloor N / 2\rfloor$ stands for the nearest integer less or equal to $N / 2$. We will not give any proof of the expression (10) nor will we tackle the question, as how to calculate the amplitudes $A_{k} \mathrm{~S}$ and the phases $\varphi_{k} \mathrm{~s}$ in this identity. Note, only that the lowest frequency $f_{k}$ of sines is zero (corresponding to $k=0$ ), and the highest possible frequency is $1 / 2$ (corresponding to $k=N / 2$ for $N$ even). The frequency increment is $1 / N$. 
If a monthly time series contains an additive seasonality, the amplitudes $A_{k} \mathrm{~s}$ corresponding to the sines with the following frequencies $f_{k}=1 / 12,2 / 12,3 / 12,4 / 12$, $5 / 12,6 / 12$ in the decomposition of the equation (10) are expected to be 'large'. And vice versa, the existence of 'large' amplitudes of sines corresponding to the above mentioned set of six frequencies might probably be attributed to the existence of seasonality in the time series. To intuitively explain, realize that seasonality means a cyclic behavior with frequency $1 / 12$ (i.e. 1 cycle per length 12 months) in a monthly time series. We can thus expect that the amplitude of the sine with the frequency $1 / 12$ should be indeed 'significantly large' in the decomposition of the equation (10) if seasonality is present. Moreover, the cyclic behavior of seasonality is generally of a non-sinusoidal shape and thus cannot be depicted correctly with only one sinusoid of frequency 1/12. It is the presence of the sines in the decomposition of the equation (10) corresponding to the frequencies which are multiples of the frequency $1 / 12$ (i.e. frequencies $2 / 12,3 / 12,4 / 12,5 / 12$ and 6/12) which in the sum help to adjust for the non-sinusoidal shape of the seasonal cycle.

The cute idea behind the representation of the time series as a sum of sines is as follows. Imagine that the time series of the log monthly inflation rate is indeed expressed as a sum of sines (call them input sines, because the log monthly inflation rate will be the input into the moving sum of the equation (8) to form the log yearly inflation rate)

$$
\log \widetilde{R R}_{m, t}=\sum_{k=0}^{\lfloor N / 2\rfloor} A_{k} \sin \left(2 \pi{ }_{k} t+\varphi_{k}\right), \quad t=0, \ldots, N-1 .
$$

We know that the equation (8) holds, which in connection with the equation (11) and the possibility to change the order of summation results in an approximate equality

$$
\begin{aligned}
\log I R_{y, t}= & \sum_{i=0}^{11} \log I R_{m, t-i} \cong \sum_{i=0}^{11} \sum_{k=0}^{\lfloor N / 2\rfloor} A_{k} \sin \left(2 \pi f_{k}(t-i)+\varphi_{k}\right)= \\
& =\sum_{k=0}^{\lfloor N / 2\rfloor} \sum_{i=0}^{11} A_{k} \sin \left(2 \pi f_{k}(t-i)+\varphi_{k}\right) .
\end{aligned}
$$

We say approximate, as the expression (12) is not totally exact, because we need past values $(t<0)$ of the time series of the log monthly inflation to calculate all the values of the time series of the $\log$ yearly inflation rate, i.e. values $\log I R_{y, t}$ with time indices $t=0, \ldots, N-1$. But the decomposition of the log monthly inflation rate into sines is valid only in the interval $0 \leq t \leq N-1$. For example the values of $\log I R_{m,-1}, \log$ $I R_{m,-2}, \ldots, \log I R_{m,-11}$ are required to calculate $\log I R_{y, 0}$ etc. The expression (12) is thus only approximate, as it does not hold for small values of $t$. The approximate relation in the sense just mentioned is denoted by ' $\cong$ '.

Anyway, expression (12) tells us that the moving sum (summation index $i$ ) is applied to every input sine separately at first, and the result is added together (summation index $k$ ) afterwards. Let us look at the effect of the moving sum applied to each input sine separately. Trigonometry tells us that

$$
\sum_{i=0}^{11} A_{k} \sin \left(2 \pi f_{k}(t-i)+\varphi_{k}\right)=c_{k} A_{k} \sin \left(2 \pi f_{k} t+\varphi_{k}+w_{k}\right),
$$


which in words means that the moving sum applied to an input sine is an output sine of the same frequency $f_{k}$ and the amplitude changed from $A_{k}$ to $c_{k} A_{k}$ and the phase changed from $\varphi_{k}$ to $\varphi_{k}+w_{k}$, where $c_{k}$ and $w_{k}$ are factors depending on $f_{k}$ only, i.e. $c_{k}=c_{k}\left(f_{k}\right)$, $w_{k}=w_{k}\left(f_{k}\right)$. We can conclude that every input sine changes its amplitude and phase to become the output sine of the same frequency. This process is illustrated in Figure 2. The input sine (full and asterisk) has the frequency $f_{k}=1 / 4$, the amplitude $A_{k}=3$, and the phase $\varphi_{k}=-\pi / 3$. The output sine (dotted and circles) has the same frequency, but a changed amplitude and phase: $c_{k}=2 / 3$ and $w_{k}=\pi / 2, \Delta T=-\pi / 2 /(2 \pi f)=-1 /(4 f)=-1$. We see that the peaks in the dotted sine are indeed coming -1 time unit after the peaks of the full sine, i.e. are coming +1 time units before the peaks of the full sine (for detailed discussion see below in the text).

Figure 2

The Input Sine (full and asterisk) and the Output Sine (dotted and circles)

Source: own calculatıons

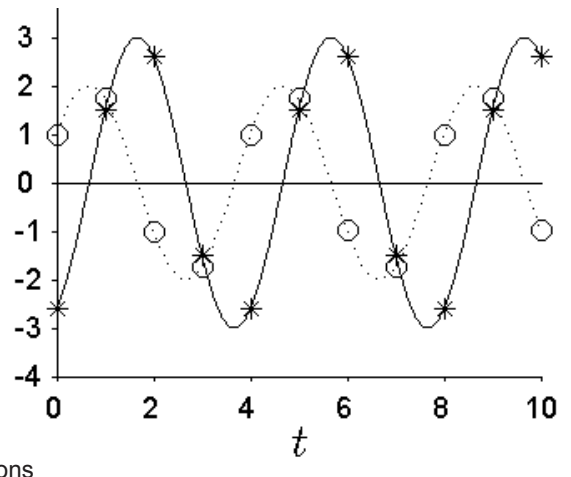

It therefore (approximately) holds that the log yearly inflation rate can be expressed as the following sum of sines

$$
\log I R_{y, t} \cong \sum_{k=0}^{\lfloor N / 2\rfloor} c_{k} A_{k} \sin \left(2 \pi f_{k} t+\varphi_{k}+w_{k}\right) .
$$

The $c_{k} \mathrm{~S}$ and $w_{k} \mathrm{~s}$ can be determined 'experimentally' by applying moving sums to each input sine separately with their frequencies in the range $0 \leq f_{k} \leq 1 / 2$ and determining the $c_{k}$ and $w_{k}$ from the 'shape' of the output sine. Or the values of $c_{k}$ and $w_{k}$ can be also derived by a pure calculation (which we will not show here).

In Figure $3 c_{k}$ is plotted against $f_{k}$. We see that the amplitudes of low-frequency input sines $\left(f_{k}<1 / 12\right)$ are much more largely amplified relatively to the amplitudes of the high-frequency input sines $\left(f_{k}>1 / 12\right)$, because $c_{k} s$ corresponding to $f_{k}<1 / 12$ are generally larger than $c_{k} s$ corresponding to $f_{k}>1 / 12$. It is also important to note that the amplitudes of input sines with frequencies equal to $1 / 12,2 / 12,3 / 12,4 / 12,5 / 12$ and 6/12 are changed to zero at the output, because $c_{k} s$ corresponding to this set of frequencies are zero. This implies that seasonal effects are not present in the log yearly inflation rate, because they have been removed by the moving sum. Note also the bumps in the figure - these may generally lead to the so called Slutzky effect. 
Figure 3

The Values of $c_{k}$ Plotted against $f_{k^{*}} c_{k}$ is Equal to Zero for Frequencies Equal to 1/12, 2/12, 3/12, 4/12, 5/12 and 6/12 which Corresponds to the Removal of Additive Seasonal Effects in the Time Series of Log Yearly Inflation Rate

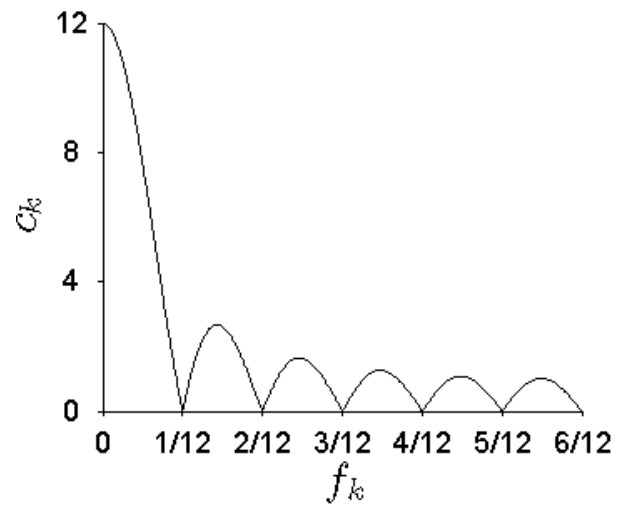

Source: own calculations

To illustrate the result, let us decompose the log monthly inflation rate and the log yearly inflation rate in the Czech Republic according to the equation (10) - the amplitudes $A_{k}$ of this decomposition are depicted in Figure 4. As the values of $A_{k}$ at frequencies $1 / 12,2 / 12,3 / 12,4 / 12,5 / 12$ and 6/12 are relatively large (except for the frequencies $3 / 12$ and 6/12) in comparison with the majority of the values, there exists a strong seasonality in the log monthly inflation rate. We can also see that this time series contains a 'great deal' of high-frequency components (i.e. quickly varying components). On the other hand the log yearly inflation rate is dominated by low-frequency components (i.e. slowly varying components), which indicates above all the presence of trend or long-run irregular cycles.

Figure 4

The Amplitudes $A_{k}$ and $c_{k} A_{k}$ of the Decomposition into Sines of a) the Log Monthly Inflation Rate, b) the Log Yearly Inflation Rate

a)

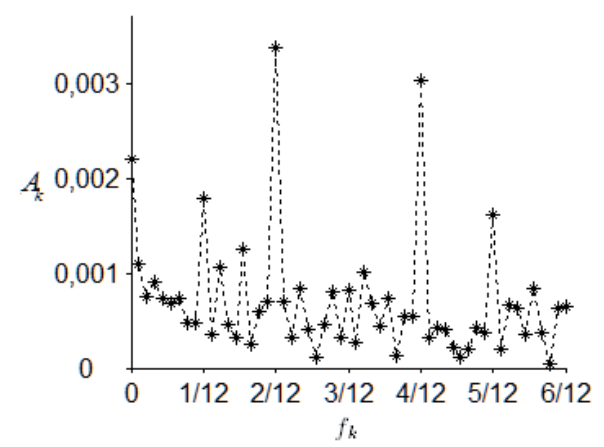

b)

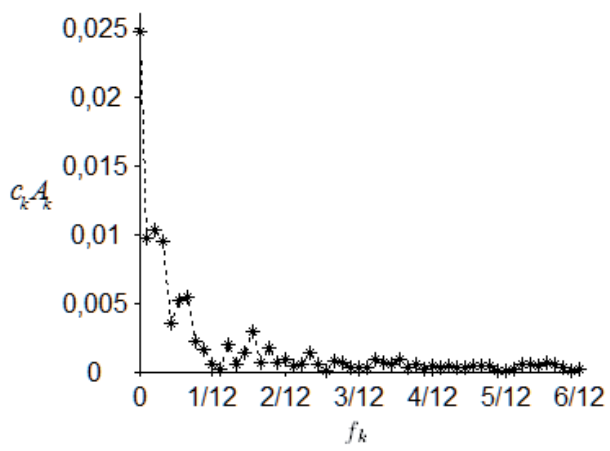




\section{The Effect of Time Delay}

A crucial point to notice is that when coming from the log monthly inflation rate to the $\log$ yearly inflation rate we take a moving sum of 12 numbers which are spread uniformly from the time $t-11$ till the time $t$ and assign the result to the time $t$. Said in a different way: the aggregate information contained in the range of times from $t-11$ to $t$ is assigned to the endpoint of this range.

The value of $\log$ yearly inflation rate at time $t$, i.e. $\log I R_{y, t}$, thus seems to be a measure of the log inflation in yearly level which effectively corresponds to time $t-5,5$ (i.e. the center of the range $t-11$ to $t$ ). This intuitively implies that the information in the log yearly inflation rate must be delayed behind the smoothed and annualized (multiplied by 12) log monthly inflation rate which truly corresponds to time $t$.

This point can be elaborated on in a more rigorous way with the help of the above introduced concept of the decomposition of the time series into sines. Let us decompose the log monthly inflation rate into sine waves (10). The equation (13) tells us that when a sine is input into the moving sum it changes its amplitude by $c_{k}$ and its phase by $w_{k}$. At this moment the $w_{k} \mathrm{~s}$ are of crucial importance for us, as they inform us about the time delay induced by the moving sum. To see this, realize that the equation (13) can be rewritten in the following way

$$
c_{k} A_{k} \sin \left(2 \pi f_{k} t+\varphi_{k}+w_{k}\right)=c_{k} A_{k} \sin \left(2 \pi f_{k}\left(t+w_{k} /\left(2 \pi f_{k}\right)\right)+\varphi_{k}\right)=c_{k} A_{k} \sin \left(2 \pi f_{k}\left(t-\Delta T_{k}\right)+\varphi_{k}\right) .
$$

We thus see that the input sine of frequency $f_{k}$ is delayed by

$$
\Delta T_{k}=-\frac{w_{k}}{2 \pi f_{k}}
$$

at the output. The dependence of $w_{k}$ and $\Delta T_{k}$ upon $f_{k}$ is plotted in Figure 5. It can be clearly seen that low $\left(f_{k}<1 / 12\right)$ frequencies are delayed each by 5 and a half a month. The fact that high frequencies $\left(f_{k}>1 / 12\right)$ are each delayed by a different amount may lead to deformations in the log yearly inflation rate.

Figure 5

The Dependence of $w_{k}$ (left) and $\Delta T_{k}$ (right) upon $f_{k}$
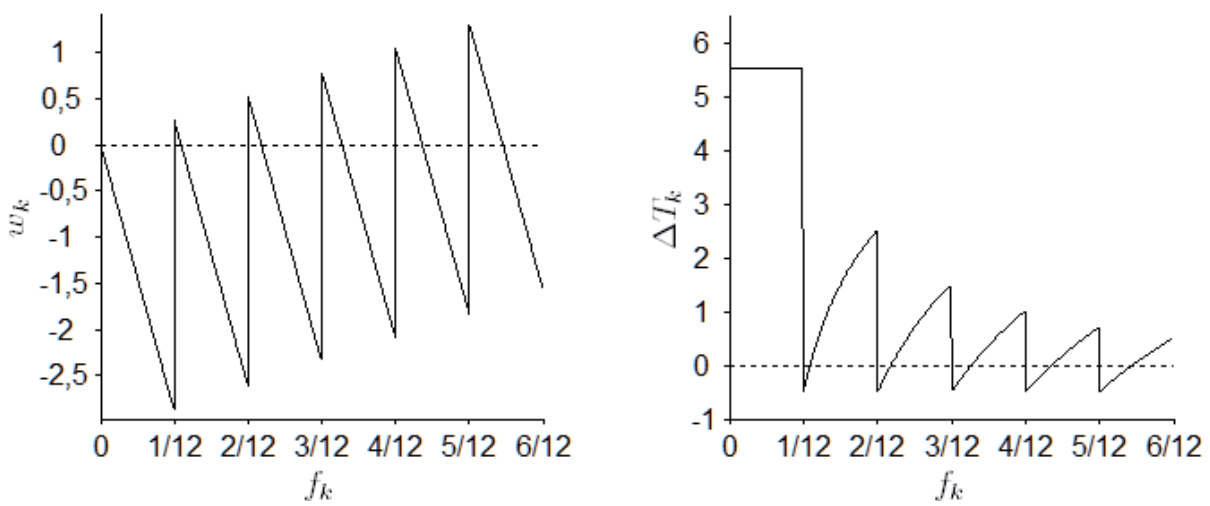

Source: own calculations 


\section{The Possible Practical Implications - Discussion}

\section{Example 1 - Yearly Inflation Rate and the Smoothed and Annualized Monthly Inflation} Rate

We have seen that the amplitudes of low-frequency $\left(f_{k}<1 / 12\right)$ input sines are mostly amplified (but not by a constant factor, as $c_{k} \mathrm{~s}$ are not constant in the range of frequencies $0<f_{k}<1 / 12$ ). At the same time these low-frequency sines are each delayed by 5.5 months. The log yearly inflation rate is thus expected to be mostly much more slowly varying when compared to the time series of the log monthly inflation rate. We also expect the log yearly inflation rate to be deformed and delayed with respect to the smoothed and annualized log monthly inflation rate. All the relations that have been found between the $\log$ yearly and the $\log$ monthly inflation rate apply also to the relation in the original scale, i.e. the relation between the yearly and the monthly inflation rate. For details see also Arlt, Bašta (2008).

The yearly inflation rate (in \%) and the smoothed and annualized monthly inflation rate (in \%) in the Czech Republic from January 1997 to July 2009 are presented in Figure 6 . The smoothing was achieved by the X12ARIMA method, annualization in the logarithmic scale by multiplication by 12 . We see that the peaks and troughs are often delayed in the log yearly inflation rate behind the smoothed and annualized time series of the log monthly inflation rate.

\section{Figure 6}

The Yearly Inflation Rate (thick) and the Annualized and Smoothed Monthly Inflation Rate

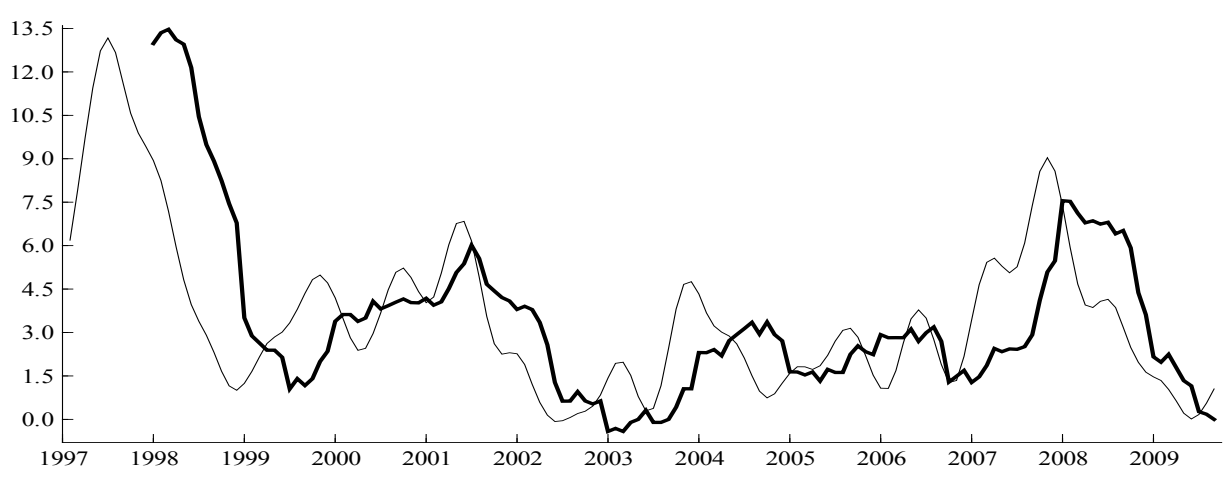

Source: own calculations, Čsú (2009)

\section{Forecasting of the Inflation in Yearly Levels}

The forecast of the correct inflation in yearly levels is crucial for the monetary policy of the central bank (see also Example 2 below). We have at least two possibilities how to proceed.

\section{Approach 1:}

The yearly inflation rate is used as a measure of the inflation in yearly levels and thus the yearly inflation rate is forecasted. For convenience, let us work in the logarithmic scale. Assume that the last observed values of the time series of the log yearly and 
the $\log$ monthly inflation rate are $\log I R_{y, T}$ and $\log I R_{m, T}$, i.e. the endpoint of both time series has a time subscript $T$. Further, assume that at time $T$ we want to obtain the forecast of the log yearly inflation rate for $h$ months ahead. Denote this forecast as $\log I R_{y, T}(h)$. We do not want to construct this forecast on the basis of the log yearly inflation rate itself but rather on the log monthly inflation rate. The reason is that the models of the log yearly inflation rate are usually of noninvertible SARIMA types, which are problematic from the point of view of parameter estimation and application for forecasting. It holds that

$$
\log I R_{y, T}(h)=\sum_{i=-5}^{+6} \log I R_{m, T}(h+i-6),
$$

where $\log I R_{m, T}(h)$ is the forecast of the log monthly inflation rate at time $T$ for $h$ months ahead.

The problem with this approach is twofold: a) the log yearly inflation rate is a delayed measure of the log inflation in yearly levels; $b$ ) the log yearly inflation rate is a deformed measure (see Fig. 3) of the log inflation in yearly levels.

\section{Illustration}

As the log yearly inflation rate is delayed approximately by 6 months, we would have to forecast it 13 months ahead to obtain a forecast of the log inflation in yearly levels 7 $(=13-6)$ months ahead. But still, such a measure of the log inflation in yearly levels would be deformed.

\section{Approach 2:}

We know that the smoothed and annualized log monthly inflation rate does not delay the information opposite to the log yearly inflation rate and at the same time provides a good measure of the log inflation in yearly levels, as it is not so deformed. This might lead to the idea to forecast the log inflation in yearly levels $h$ months ahead as

$$
12 \times\left.\log I R_{m, T}(h)\right|_{\text {smoothed }} .
$$

From a quick view at equation (15) it might look like that this approach requires the forecast of log monthly inflation rate $h$ months ahead. However, this is not true as proper smoothing requires values coming before and also after the time of the smoothed value. Thus, in order to obtain a smoothed value $\left.\log I R_{m, T}(h)\right|_{\text {smoothed }}$ we have to have values coming after the time $T+h$.

\section{Illustration}

As in the case 1 we discuss the forecast of the log inflation in yearly levels 7 months ahead with the use of equation (15). It holds that this forecast is equal to

$$
12 \times\left.\log I R_{m, T}(7)\right|_{\text {smoothed }} .
$$

However, to obtain the smoothed value $\left.\log I R_{m, T}(7)\right|_{\text {smoothed }}$ we have to forecast the time series of $\log I R_{m, t}$ more than 7 months ahead. How many months ahead would be needed depends on the applied smoothing procedure (typically X12ARIMA methodology (see 
for example Arlt, 1996, U.S. Census Bureau Washington, DC, 2002) is implemented) and also on the mean square error of the forecasts. Recall that in the case of approach 1 the log monthly inflation rate had to be forecast 13 months ahead.

\section{Conclusion:}

Now, there is a question which of the two mentioned approaches to forecasting of the $\log$ inflation in yearly levels is better. It depends on the applied smoothing procedure, on the mean square error of the forecast of the log monthly inflation rate several months ahead, on the extent to which the log yearly inflation rate is (beyond the time delay) a deformed measure of the log inflation in yearly levels and also on the extent to which the smoothed and annualized log monthly inflation rate is not a deformed measure. It follows that without the definition of the term inflation in yearly level it cannot be answered directly which of these two approaches is better.

\section{Example 2 - Yearly Inflation Rate and Transmission of Monetary Politicy to Economy}

One of the most important monetary-political objectives of the Bank Board of the Czech National Bank (CNB) is the setting of the two-week repo rate. In CNB, 2008c it is written: "Banks have the option of depositing their excess liquidity at the CNB for a two-week period on the basis of repurchase agreements ("repos") at a rate not exceeding the two-week repo rate. By changing the repo rate, the CNB influences short-term interest rates on the interbank market. This signal then spreads to interest rates throughout the economy, to the economic activity and ultimately to inflation."

In the same material in connection with monetary policy it is also stated: "Owing to the lag that arises between the implementation of a monetary policy measure and its greatest impact on inflation, the CNB's monetary policy decision-making is guided not by the present situation but by the forecast of the future - rather like someone deciding what to put on when leaving home in the morning does not act according to the weather outside but rather according to the forecast for the whole day. Consequently, the CNB concentrates on the period about 12-18 months ahead (the so-called monetary policy horizon) in its monetary policy deliberations, although of course it also takes into account developments before and after this period."

The forecast is published quarterly by CNB in the Inflation Report. In the Introduction of the Inflation Report for the third quarter of 2009 it is among others written: "The forecast of the inflation at the "monetary policy horizon" (about 12-18 months ahead) is of the greatest relevance to the decision-making on the current interest rate settings." Afterwards, it is stated in the inflation report: "The forecast is the key input - but not the only one - to the decision-making of the Bank Board. At its meetings during the quarter, the Bank Board discusses the current forecast and the balance of risks and uncertainties surrounding it. The arrival of new information since the forecast is drawn up. The possibility of asymmetric assessment of the risks of the forecast, divergent views of some board members on the development of the external environment or the linkages between the various indicators within the Czech economy mean that the final decision of the Bank Board need not be in agreement with the message of the forecast."

In the process of the creation of monetary policy, besides the "headline inflation" the "monetary-policy relevant inflation" is also of great importance. The latter is adjusted for the first-round effects of changes of indirect taxes. In the minutes of the 
Bank Board Meeting of 25 June 2009 it is written: "It was said that monetary policy should not react to short-term fluctuations in food and oil prices." Consequently, for the monetary policy the "adjusted inflation excluding fuels" is important, which represents the price dynamics of nonfood consumer basket items without items with regulated prices, administrative interventions and fuels.

In the light of this statement we will try to assess the relevance of the adjusted inflation excluding fuels for the setting the two-week repo rate (in further text only "repo rate"). Figure 7 shows the relationship of the repo rate (REPO) and the yearly adjusted inflation rate $\left(I R_{y, a d j}\right)$ from January 2003 to September 2009 (the last two values of $I R_{y, a d j}$ are the CNB's forecasts). This figure indicates that the development of both time series is similar to a great extent. Interesting is the period approximately from the half of year 2007 to the first quarter of 2008. The behavior of time series in this time is distinct, the repo foreruns the yearly adjusted inflation rate approximately by about a half of a year. In these circumstances there is a question if there is still another possible source of information for the repo rate setting. The third time series on the Figure 7 is the euro area repo rate $\left(R E P O_{e c b}\right)$. It is obvious that from the half of 2003 to the November of 2005 it is constant contrary to the rest of time series. In the period from the half of year 2007 to the first quarter of 2008 the euro area repo foreruns even the repo. It is known that in this period the rise in the consumer price inflation was largely due to food prices and regulated prices (CNB, 2008b). This cannot be catched by the adjusted inflation rate but by the yearly inflation rate and it could be anticipated by the monetary authority. It seems that also in this period the repo setting was drawn more by the yearly adjusted inflation rate than by the euro area repo rate. The development of all analyzed time series from September 2008 is the same, they sharply decline. It can be concluded from Figure 7 that it seems that there are some similarities in the development of the analyzed time series and therefore it is helpful to analyze their relationships by econometric methods.

\section{Figure 7}

Two-Week Repo Rate (thick), Yearly Adjusted Inflation Rate (thin) and Euro Area Repo Rate

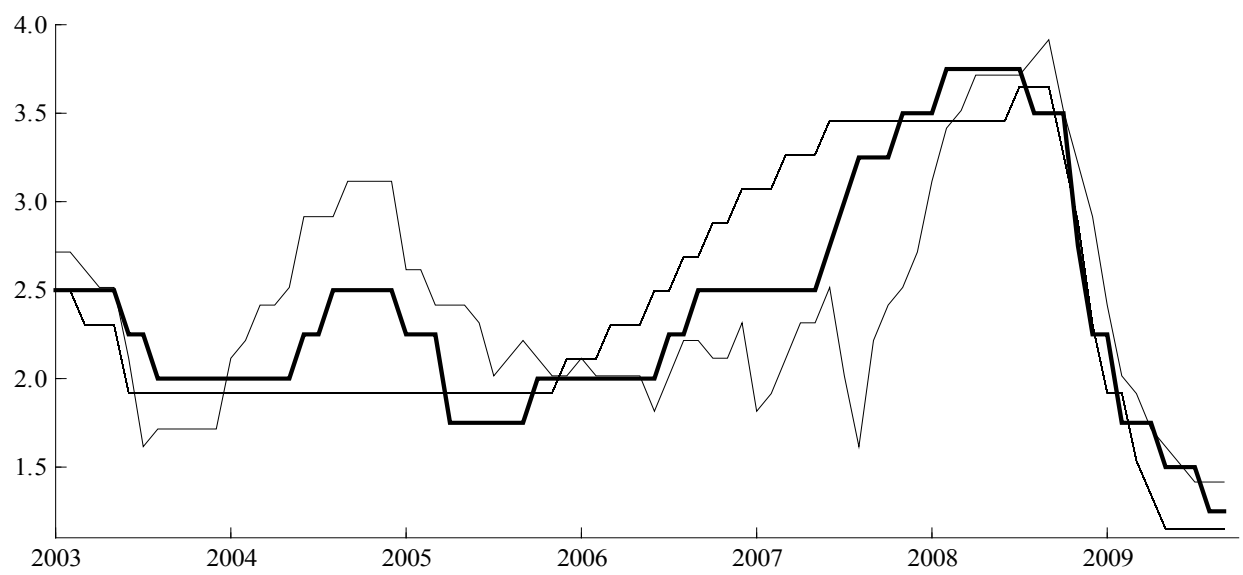

Note: Time series are recounted to have the same average and variance.

Source: own calculations, CNB (2009), ECB (2009) 
We will apply the cointegration analysis based on the VAR model. The analysis period is from January 2003 to September 2009 (because of the availability of the data). We are aware of the problem of short time series and will not overrate the results. On the other hand, we believe this analysis will contribute to the discussion about the CNB's monetary policy.

To implement the cointegration analysis, the test of unit root of individual time series has to be made. The ADF unit root test does not prove the stationarity of either of the analyzed time series $\left(t_{A D F_{R E P O}}=-2.361(0.156), t_{A D F_{\mathbb{R}}}=-1.878(0.341), t_{A D F_{R E P O} E C B}\right.$ $=-1.627(0.464))$. We will suppose they are of $I(1)$ type (in the fact due to the jump behavior of the repo rate the test indicates this time series is on the threshold of $I(1)$ and $I(2)$ type). To depict the distinct time series behavior in the period from July 2007 to April 2008, the zero-one dummy variable $(D 1)$ is defined.

The analysis of the residual autocorrelation, heteroscedasticity and normality and relatively short time series suggest a VAR(2) model with a constant and a dummy variable. It can be written as

$$
\left[\begin{array}{c}
R E P O_{t} \\
I R_{y, a d j, t} \\
R E P O_{e c b, t}
\end{array}\right]=\left[\begin{array}{c}
\dot{c}_{1} \\
\dot{c}_{2} \\
\dot{c}_{3}
\end{array}\right]+\left[\begin{array}{ccc}
\dot{\phi}_{1,11} & \dot{\phi}_{1,12} & \dot{\phi}_{1,13} \\
\phi_{1,21} & \dot{\phi}_{1,22} & \phi_{1,23} \\
\dot{\phi}_{1,31} & \phi_{1,32} & \dot{\phi}_{1,33}
\end{array}\right]\left[\begin{array}{c}
R E P O_{t-1} \\
I R_{y, a d j, t-1} \\
R E P O_{e c b, t-1}
\end{array}\right]+\left[\begin{array}{ccc}
\phi_{2,11} & \phi_{2,12} & \dot{\phi}_{2,13} \\
\phi_{2,21} & \dot{\phi}_{2,22} & \dot{\phi}_{2,23} \\
\dot{\phi}_{2,31} & \phi_{2,32} & \dot{\phi}_{2,33}
\end{array}\right]\left[\begin{array}{c}
R E P O_{t-2} \\
I R_{y, a d j, t-2} \\
R E P O_{e c b, t-2}
\end{array}\right]+\left[\begin{array}{c}
\dot{\delta}_{1} \\
\delta_{2} \\
\delta_{3}
\end{array}\right] 1_{t}+\left[\begin{array}{c}
a_{1 t} \\
a_{2 t} \\
a_{3 t}
\end{array}\right] .
$$

The parameter estimates statistically significantly different from zero (5\% significant level) are marked by a dot. It can be seen that the repo rate at time $t$ depends on the repo rate at time $t-1$, on the yearly adjusted inflation rate at $t-1$ and on the euro area repo rate at $t-1$ and $t-2$. The inflation rate at time $t$ depends on the inflation rate at $t-1$ and $t-2$ and on the euro area repo rate at $t-2$. The euro area repo rate at $t$ depends on the repo rate at $t-1$ and $t-2$ and on the euro area repo rate at $t-1$ and $t-2$. Nevertheless, due to the nonstationary system and the risk of the spurious correlations these results should not be overrated.

The Johansen cointegration test (Trace test) identifies the presence of one cointegration relationship and two common trends. This leads to the reduction of the $\operatorname{VAR}(2)$ model into the VEC model

$\left[\begin{array}{c}\Delta R E P O_{t} \\ \Delta I R_{y, a d j, t} \\ \Delta R E P O_{e c b, t}\end{array}\right]=\left[\begin{array}{ccc}\Gamma_{1,11} & \Gamma_{1,12} & \Gamma_{1,13} \\ \Gamma_{1,21} & \Gamma_{1,22} & \Gamma_{1,23} \\ \Gamma_{1,31} & \Gamma_{1,32} & \Gamma_{1,33}\end{array}\right]\left[\begin{array}{c}\Delta R E P O_{t-1} \\ \Delta I R_{y, a d j, t-1} \\ \Delta R E P O_{e c b, t-1}\end{array}\right]+\left[\begin{array}{c}\alpha_{1} \\ \alpha_{2} \\ \alpha_{3}\end{array}\right]\left[\begin{array}{lllll}\beta_{1} & \beta_{2} & \beta_{3} & \rho_{1} & \rho_{2}\end{array}\right]\left[\begin{array}{c}R E P O_{t-2} \\ I R_{y, a d j, t-2} \\ R E P O_{e c b, t-2} \\ D 1_{t} \\ 1\end{array}\right]+\left[\begin{array}{c}a_{1 t} \\ a_{2 t} \\ a_{3 t}\end{array}\right]$,

where the estimated and transformed (estimated parameter of variable $R E P O$ equals one) parameters of the cointegration vector has the form

$$
\hat{\boldsymbol{\beta}}^{\prime}=\left[\begin{array}{llll}
\hat{\beta}_{1} & \hat{\beta}_{2} & \hat{\beta}_{3} & \hat{\sigma}_{1} \\
\sigma_{2}
\end{array}\right]=\left[\begin{array}{lllll}
1.000 & -0.521 & -0.339 & -0.576 & -0.986
\end{array}\right] .
$$

These estimates directly show the directly proportional long-run relationship of $R E P O$, $I R_{y, a d j}$ and $R E P O_{e c b}$.

It is helpful to test the system for the weak exogeneity, namely the hypothesis about parameters $\boldsymbol{\alpha}^{\prime}=\left[\begin{array}{lll}\alpha_{1} & \alpha_{2} & \alpha_{3}\end{array}\right]$. The parameters of interest are cointegration parameters $\boldsymbol{\beta}$. Only parameter $\alpha_{3}$ was not proved to be different from zero ( $L R=1.851$ $(0.174))$, consequently the euro area repo rate can be assumed to be weakly exogenous 
for long run parameters $\boldsymbol{\beta}$. This means that the model of $\triangle R E P O_{e c b, t}$ does not contain any information about $\boldsymbol{\beta}$. In this case it is valid to proceed the cointegration analysis

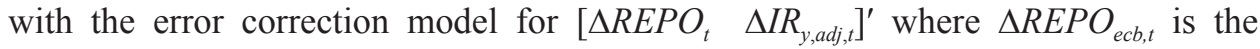
conditional variable. This result has the following interpretation: The development of the euro area repo rate (the particular values of process parameters) does not impose any space restrictions for the long-run relationship. On the other hand as the week exogeneity was not proved for the yearly adjusted inflation rate the change of the shape of its behavior (the process parameters change) can lead to some form of adjustment of the long-run relationship and therefore this time series cannot be considered as a conditional variable.

The estimated cointegration vector under the restriction of weak exogeneity of $\triangle R E P O_{e c b, t}$ has the form

$$
\hat{\boldsymbol{\beta}}^{\prime}=\left[\begin{array}{llll}
1.000 & -0.474-0.346 & -0.539 & -1.009
\end{array}\right] .
$$

It is similar to the estimated cointegration vector in the unrestricted system. The Figure 8 shows the long-run relationship which is by assumption stationary.

Figure 8

The Cointegration Relationship Based on the Model (17) under the Weak Exogeneity Restriction

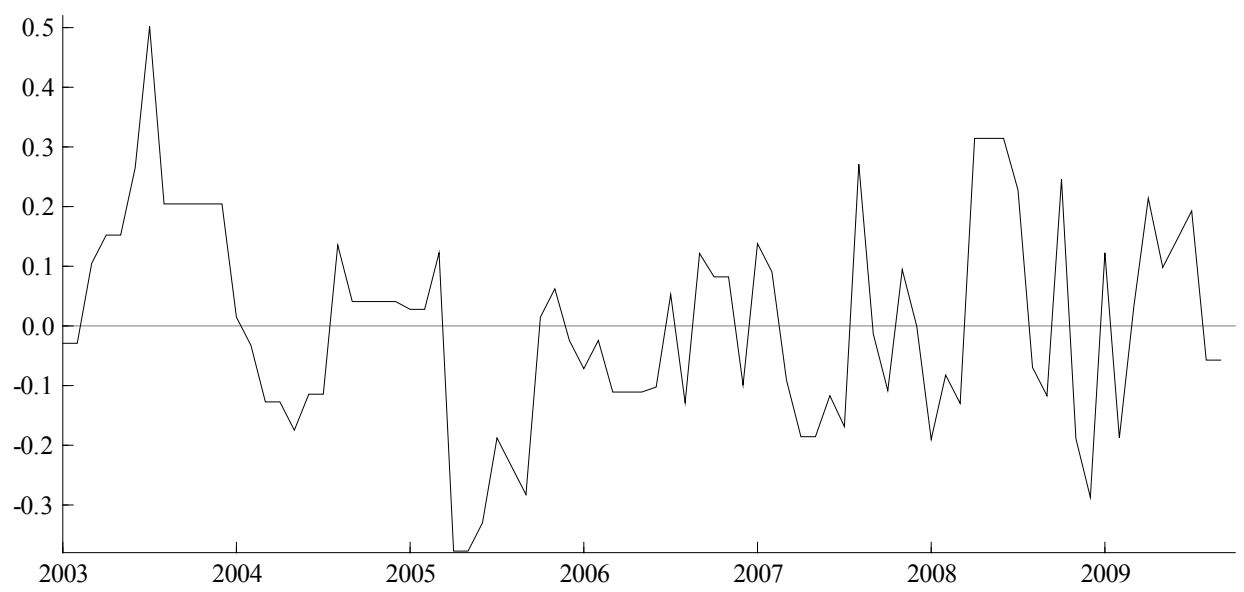

Source: own calculation

From the cointegration analysis it follows that the repo rate, the yearly adjusted inflation rate and the euro area repo rate have one long-run relationship and two common trends. It seems that the deformations of the yearly inflation rate (especially the time delay) are transmitted into the repo rate.

Figure 9 shows the development of the repo rate and the interest rates of the financial market i.e. the time series M1PRIBOR, M3PRIBOR and R1PRIBOR. The relationship of these time series in the period from January 2003 to September 2009 was specified by cointegration analysis based on the VAR model with a zero-one dummy variable D2, which balances the sharp fall in the time series from October 2008. The ADF 
unit root test indicates that the interest rates of the financial market are of I(1) type $\left(t_{A D F_{M 1 P R I B O R}}=-1.467(0.545), t_{A D F_{M 3 P R I B O R}}=-1.599(0.478), t_{A D F_{R I P R I B O R}}=-1.742(0.406)\right)$.

From the character of the data and the residual analysis it follows that in all three cases the two dimensional VAR(4) model catches the data autocorrelation structure sufficiently. The Johansen cointegration test reveals the presence of the long-run relationship in all three cases. In all cases the error correction part in VEC model has a form

$$
\left[\begin{array}{l}
\alpha_{1} \\
\alpha_{2}
\end{array}\right]\left[\begin{array}{llll}
\beta_{1} & \beta_{2} & \rho_{1} & \rho_{2}
\end{array}\right]\left[\begin{array}{c}
\text { PPRIBOR }_{t-4} \\
\operatorname{REPO}_{t-4} \\
D 2_{t} \\
1
\end{array}\right], \quad i=M 1, M 3, R 1,
$$

where the estimated and transformed cointegration parameters are

$$
\begin{aligned}
& i=M 1: \quad \hat{\boldsymbol{\beta}}^{\prime}=\left[\begin{array}{llll}
\hat{\beta}_{1} & \hat{\boldsymbol{\beta}}_{2} & \hat{\rho}_{1} & \hat{\rho}_{2}
\end{array}\right]=\left[\begin{array}{llll}
1.000 & -0.893 & 0.424 & -0.208
\end{array}\right], \\
& i=\mathrm{M} 3: \hat{\boldsymbol{\beta}}^{\prime}=\left[\begin{array}{llll}
1.000 & -0.832 & 0.640 & -0.292
\end{array}\right], \\
& i=R 1: \quad \hat{\boldsymbol{\beta}}^{\prime}=\left[\begin{array}{llll}
1.000 & -0.855 & 0.989 & -0.045
\end{array}\right] \text {. }
\end{aligned}
$$

As other financial market rates behave very similarly to those mentioned above, it is possible to anticipate their cointegration with the repo rate, too.

\section{Figure 9}

\section{From Bottom to Top: Two-Week Repo Rate, M1PRIBOR (thin), M3PRIBOR and R1PRIBOR}

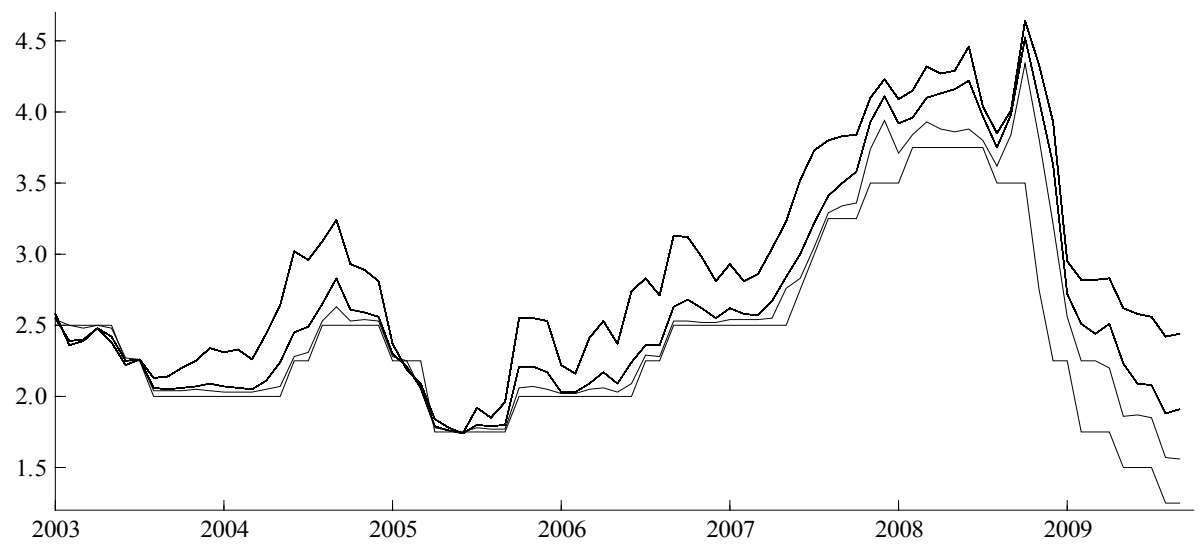

Source: CNB (2009)

In the Inflation Report for the second quarter of 2009, Box 1 there is an introduction to the quantitative assessment of the transmission of the financial market interest rates to the retail interest rates based on the cointegration analysis. In the first item it is stated: "The effectiveness of the transmission of the monetary policy into the economy depends on how the interest rate conditions for credit financing of non-financial corporations and households are affected by financial market interest rates." From 
the empirical analysis for the period of 2003-2008 years it follows that the interest rate on loans to non-financial corporations with a rate fixation of up to one year is in the case of small loans cointegrated with 1RPRIBOR and in the case of large loans with the 3MPRIBOR. For housing loans the cointegration analysis showed the relationship with the gross yield on the 10Y government bond and with the 1MPRIBOR. The rates for deposits with an agreed maturity of up to two years and over two years are cointegrated with the 1 MPRIBOR and the 3MPRIBOR respectively.

The Delay of the Monetary Policy Transmission to the Retail Interest Rates and its Implications

The form of relationship of the yearly adjusted inflation rate and the retail interest rates is apparent from the above mentioned empirical analysis. In the previous parts of this paper we demonstrated that the yearly inflation rate is characteristic by the delay of information by about 6 months with respect to the monthly inflation rate. This is valid also for the yearly adjusted inflation rate. It follows that owing to the presence of the long-run relationship between the repo rate, the financial market interest rates and the retail interest rates, all these interest rates are probably set up also with 6 month delay. Figure 10, which shows the development of the yearly adjusted inflation rate, the repo rate and the annualized and smoothed inflation rate, illustrates this delay. Only the annualized and smoothed monthly inflation rate is not delayed and from this point of view it represents a more realistic indicator of inflation in the yearly level as compared to the yearly adjusted inflation rate.

If the end values of the annualized monthly inflation rate are properly smoothed, it is seen in Figure 10 that the yearly adjusted inflation rate has the potential to grow from September 2009 to February 2010.

Figure 10

Two-Week Repo Rate (thick), Yearly Adjusted Inflation Rate (thin) and Annualized and Smoothed Monthly Inflation Rate

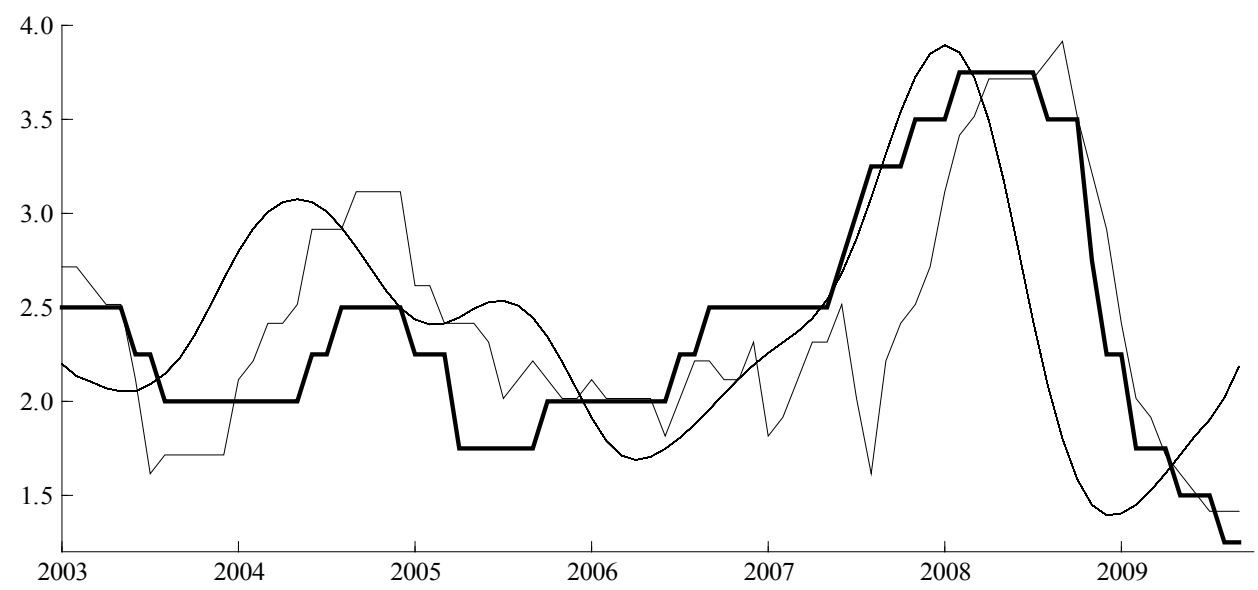

Note: Time series are recounted to have the same average and variance.

Source: own calculation, CNB (2009) 
In this connection it is interesting to compare also the development of the euro area repo rate, the yearly inflation rate based on the euro area HICP and the annualized and smoothed monthly inflation rate based on the euro area HICP. Figure 11 shows, that the sharp decline of the euro area repo rate and the euro area yearly inflation rate in the period from September 2008 is the same. The time delay of these time series behind the euro area annualized and smoothed inflation rate is clearly apparent in this economically unstable period.

Figure 11

Euro Area Repo Rate (thick), Euro Area Yearly Inflation Rate (thin) and Euro Area Annualized and Smoothed Inflation Rate

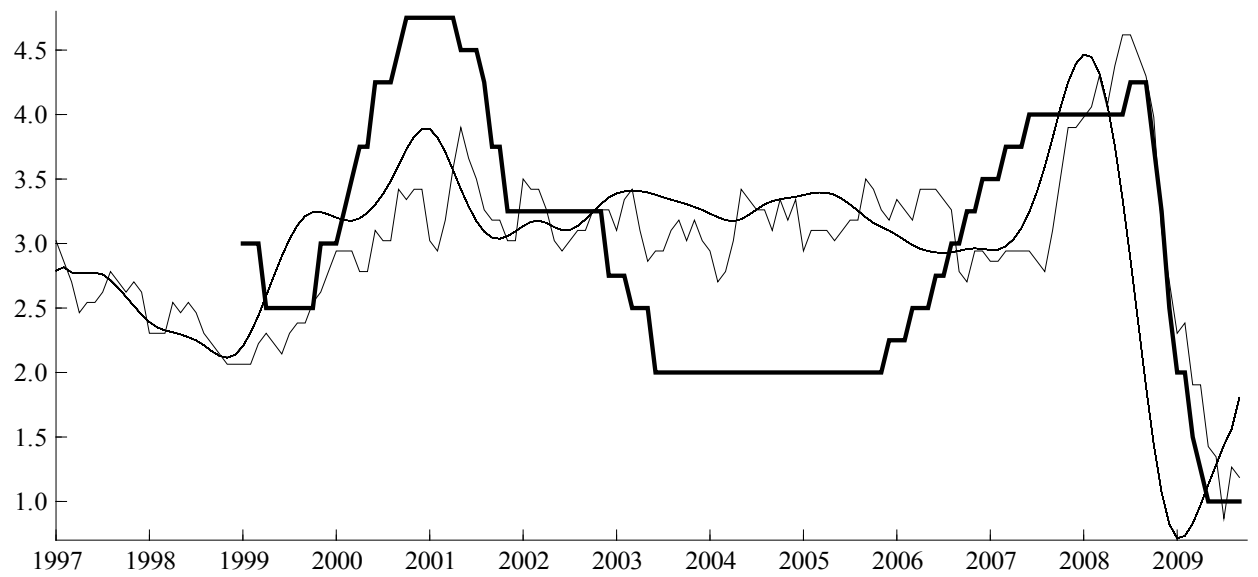

Note: Time series are recounted to have the same average and variance.

Source: own calculation, ECB (2009)

\section{Conclusion}

In this paper we have analyzed the properties of one of the most frequently applied measures of inflation in yearly levels namely the yearly inflation rate. With the help of harmonic analysis we have shown that the yearly inflation rate deforms and delays the information contained in the monthly inflation rate and thus is also delayed behind the true inflation in yearly levels. This conclusion can be extremely important in the forecasting of the inflation rate in yearly levels and in the process of economic decisions.

The practically applicable indicator of the inflation in yearly levels is the annualized and smoothed monthly inflation rate. This measure does not delay information, but the problem is with its seasonal and random components which have to be removed. The removal of these components can be achieved by applying a smoothing operation for which the values that come before and after the time of the smoothed value are needed which is problematic especially for the values at the end of the time series where good forecasts are thus required. 
The problem of the yearly inflation rate is illustrated on the example of the monetary policy transmission of CNB. On the basis of the empirical analysis we have shown the long-run character of the relationship of the repo rate, the yearly adjusted inflation rate and the euro area repo rate. The yearly adjusted inflation rate is delayed by approximately 6 months with respect to the true inflation in yearly levels. Owing to the presence of the long-run relationship between the repo rate, the financial market interest rates and the retail interest rates, it seems that also these interest rates are delayed.

\section{References}

Arlt, J. (1996), "Metoda X11ARIMA." Statistika, Vol. 33, No. 1-7.

Arlt, J. (1998), "Problém krátkodobé a dlouhodobé míry inflace. (The Problem of Short-term and Long-term Inflation Rate).” Politická ekonomie. 1998, Vol. 46, No. 5, pp. 667-674.

Arlt, J., Arltová, M. (1999), "The Problem of the Rate of Inflation." Acta Oeconomica Pragensia, 1999, Vol. 7, No. 4, pp. 7-12.

Arlt, J., Arltová, M. (2009), Ekonomické časové raady. Praha: Professional Publishing, 2009.

Arlt, J., Bašta, M. (2008), "Časové řady měsíční a roční míry inflace a jejich vlastnosti (Time Series of Monthly and Yearly Inflation Rates and their Properties)." Politická ekonomie. 2008, Vol. 56, No. 4, pp. 536-556.

Arlt, J., Bašta, M., Arltová, M. (2009), "The problem of the Yearly Inflation Rate and its Solution." Cagliari 30. 5. 2009 - 3. 6. 2009. In EURISBIS'09. Cagliari: Tilapia, 2009, pp. 28-29.

Brada, J., Brůna, K. (2004), "Analýza citlivosti referenčních úrokových sazeb PRIBOR na změny repo sazby České národní banky (An Analysis of PRIBOR Interest Rates Sensitivity to Changes in Czech National Bank Repo Rate)." Politická ekonomie. 2004, Vol. 51, No. 5, pp. 601-622.

Brůna, K. (2009), "Měnová politika a predikce variability úrokových sazeb na peněžním trhu (Monetary Policy and Prediction of Variability)." Politická ekonomie. 2009, Vol. 57, No. 3, pp. 361-382.

CNB (2008a), Inflation Report/l. Czech National Bank, 2008. http://www.cnb.cz/en/monetary_policy/ inflation_reports/index.html

CNB (2008b), Inflation Report/II. Czech National Bank, 2008. http://www.cnb.cz/en/monetary_policy/ inflation_reports/index.html

CNB (2008c), Fact Sheet. Czech National Bank, 2008. www.cnb.cz/en/public/publications/download/ mp_fact_sheet_en.pdf

CNB (2009), ARAD - system časových řad. http://www.cnb.cz/docs/ARADY/HTML/index.htm

CNB (2009), Inflation Report/II. Czech National Bank, 2009. http://www.cnb.cz/en/monetary_policy/ inflation_reports/index.html

CNB (2009), Inflation Report/III. Czech National Bank, 2009. http://www.cnb.cz/en/monetary_policy/ inflation_reports/index.html

CSU (2009), http: //www.czso.cz/csu/redakce.nsf///mira_inflace

ECB (2009), Statistical Data Warehouse. http://sdw.ecb.europa.eu/

Mandel, M. (2009), "Milníky české měnové politiky." (The Milestones at the Czech Monetary Policy) Přednáška na konferenci 20 let finančních a bankovních reforem v České republice, pořádané ČNB a VŠE 11. 11. 2009 v Praze.

Percival, D. (1993), Spectral Analysis for Physical Applications. Cambridge, UK: Cambridge University Press.

U.S. Census Bureau (2002), X-12-ARIMA Reference Manual. Washington DC, 2002. http://www. census.gov/srd/www/x12a 